\title{
Coefficient of Friction between Tool and Material in Shearing*
}

\author{
Masahiro SASADA**, Kazuki SHIMURA*** and Isamu AOKI**
}

\begin{abstract}
In this study, we propose a method of determining the coefficient of friction between a tool flank and a sheared surface in shearing. In this method, the vertical force and horizontal force need to be measured after completion of the separation process, after which the coefficient of friction is defined as the ratio of vertical force to horizontal force. In this study, the influences of punch speed, kinematic viscosity of lubricating oil and clearance on the coefficient of friction were investigated. Using the proposed method, a coefficient of friction of about 0.35 was obtained when ordinary lubricating oil was used. The coefficient of friction between the tool face and the material surface was also determined from sliding friction tests. The results of Finite Element Method taking into account the coefficients of friction obtained by the method showed good agreement with experimental results for the piercing of small holes.
\end{abstract}

Key Words: Plastic Working, Shearing, Tool, Friction, Finite Element Method, Measuring Method

\section{Introduction}

Further advancement of the shearing technique is anticipated and desired, because this technique is widely applied to the manufacture of industrial components owing to its high production rate and stability. To fundamentally advance the shearing technique, its mechanism should be analyzed by traditional methods ${ }^{(1)}$ as well as by the finite element method ${ }^{(2)-(8)}$. In whichever case, estimation of the coefficient of friction between the tool surface and material surface is unavoidable. The shearing process seems to be simple at first glance; however, its analysis is not easy because the process is unsteady, and forces and relative sliding length vary at different locations on the tool. Adhesion and seizing are apt to occur at the punch flank accompanying the generation of the virgin surface of the material. The estimation of the coefficient of friction is therefore difficult in shearing. Although the frictional states vary at different locations on the tool, the reason why the coefficients of friction of the tool flank and tool

* Received 19th July, 2006 (No. 05-0606). Japanese Original: Trans. Jpn. Soc. Mech. Eng., Vol.71, No.712, C(2005), pp.3583-3589 (Received 2nd June, 2005)

** Department of Mechanical Engineering, Kanagawa University, 3-27-1 Rokkakubashi, Kanagawa-ku, Yokohama 221-8686, Japan

*** Graduate School of Engineering, Kanagawa University, 3-27-1 Rokkakubashi, Kanagawa-ku, Yokohama 2218686, Japan face are set to 0.1 in analysis lies in the difficulty of measurement. There are many reports on the measurement of the coefficient of friction in metal forming, but none of the measurements are directly carried out in shearing tests. Although the coefficient of friction between the tool flank and the virgin surface obtained by a cutting experiment ${ }^{(9)}$ is similar to that during shearing, the friction mechanism is different. It is therefore ideal to measure the coefficient of friction during shearing. Furthermore, it is also necessary to measure the coefficient of friction between the tool face and the material surface. It is known that the friction of the tool flank affects the forming characteristics in small-hole piercing ${ }^{(7),(8)}$. Because of this, the measurement of the coefficient of friction has significance in both engineering and industry.

In this study, a method of determining the coefficient of friction between a tool flank and a sheared surface in shearing is proposed. The proprieties of the coefficient of friction were confirmed from the results of Finite Element Method on small-hole piercing.

\section{Problems Related to Friction in Shearing}

Figure 1 shows a schematic drawing of the principle of shearing. The metal sheet is pressed on a die by using a blank holder and pierced by using a punch. Friction in shearing consists of three states because the frictional mechanism varies in accordance with to the location on the tool.

(1) Friction between tool flank and sheared surface 


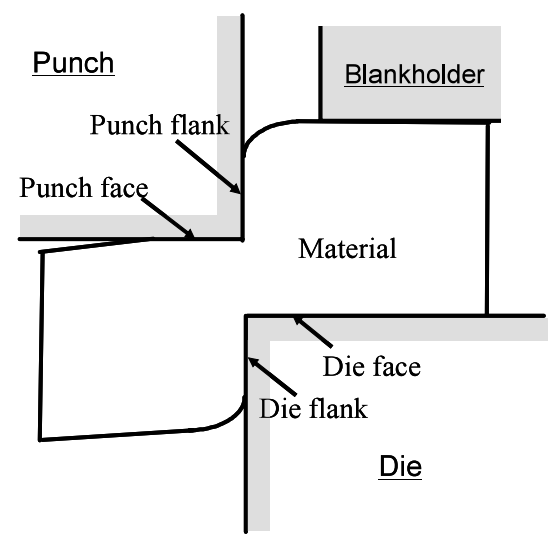

Fig. 1 Principle of shearing

(virgin surface) of material

It is thought that the coefficient of friction is high because the punch flank and die flank are in contact with the virgin surface of the specimen.

(2) Friction between tool face and material surface The tool face is in contact with the surface of the specimen. There is little virgin surface. Thus, it is thought that the coefficient of friction is lower than that in case 1 , but the frictional state is similar to those of drawing and bending.

( 3 ) Friction between surface of blank holder and material surface

Because the specimen is pressed onto a die by the blank holder, the surface of the blank holder is in contact with the surface of the specimen. Except in special processes such as fineblanking, this friction state is similar to the friction state of the tool face.

The friction states vary in accordance with the location on the tool. It is therefore necessary to take into account the different frictional states in the analysis as well as to determine the coefficient of friction in shearing.

\subsection{Method of determining the coefficient of fric- tion}

It is easy to determine the coefficient of friction between the tool face and the surface of the specimen by experiments simulating shearing. On the other hand, because it is difficult to determine the coefficient of friction between the punch flank and the virgin surface of the material by experiments, the method of determining the coefficient of friction during shearing is also reviewed in this study.

Figure 2 shows the forces acting on the tool before separation in single-side shearing. The shearing force $\mathrm{F}$ can be expressed using Eq. (1), and the horizontal force can be expressed using Eq. (2).

$$
\begin{aligned}
& F=V_{p}+\mu_{v} H_{p} \\
& H=H_{p}+\mu_{n} V_{p}
\end{aligned}
$$

Normal force on punch face: $V_{p}$

Normal force on die face: $V_{d}$

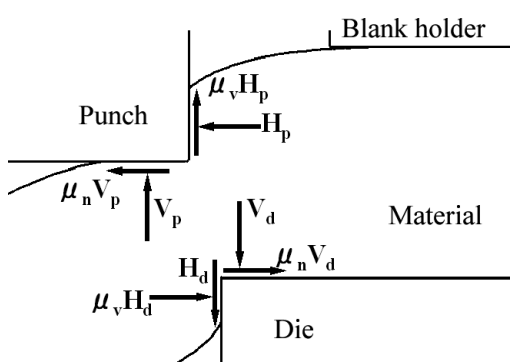

Fig. 2 Forces acting on tool during fixed type shearing before separation

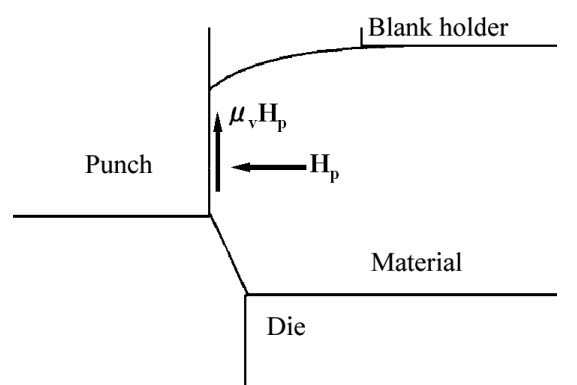

Fig. 3 Forces acting on tool during fixed type shearing after separation

Normal force on punch flank: $H_{p}$

Normal force on die flank: $H_{d}$

Coefficient of friction of punch flank and die flank: $\mu_{v}$

Coefficient of friction of punch face and die face: $\mu_{n}$

Shearing force: $F$

Horizontal force: $H$

The calculation of the coefficients of friction is difficult using Eqs. (1) and (2), because the state of forces on the tool is complicated before separation. Figure 3 shows the forces on the tool after separation. The normal force on the punch face becomes 0. By applying Eqs. (1) and (2), Eqs. (3) and (4) are obtained.

$$
\begin{aligned}
& F=\mu_{v} H_{p} \\
& H=H_{p}
\end{aligned}
$$

Then

$$
\mu_{v}=F / H
$$

The shearing force and horizontal force are necessary for calculating the coefficient of friction. The shearing force and horizontal force are measured during the pushing and stripping processes after separation, after which the coefficient of friction is calculated using Eq. (5).

The frictional state after separation is different from that before separation. However, the forces between the punch flank and the virgin surface of the material can be measured by the proposed method. Since there are no alternative methods at present, the proposed method was used to determine the coefficient of friction in this study. 


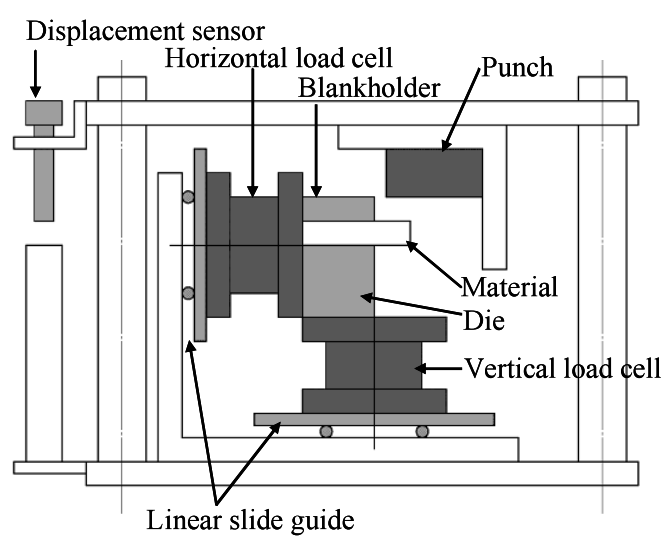

Fig. 4 Main part of experimental apparatus

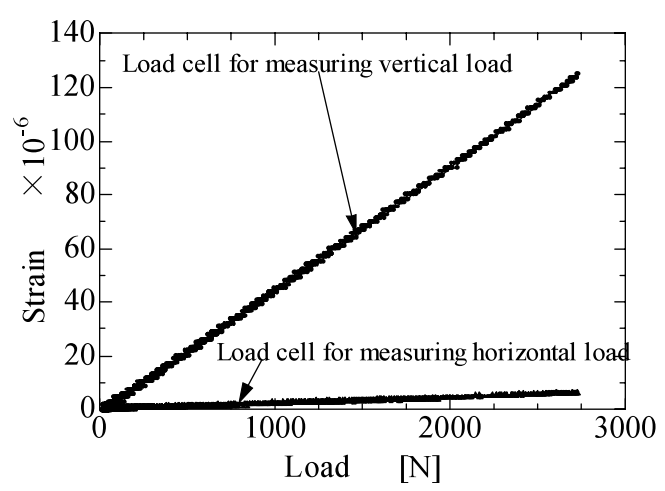

(a) Load vertically applied

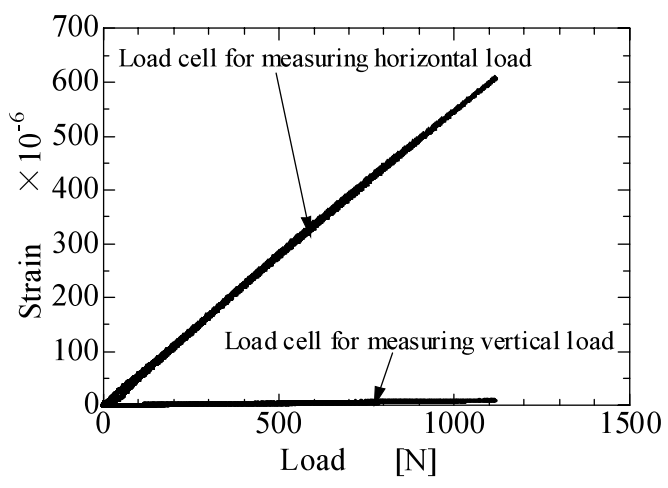

(b) Load horizontally applied

Fig. 5 Calibration diagrams of load cell

\section{Experimental Method and Conditions}

\subsection{Experimental conditions}

Figure 4 shows the main part of the experimental apparatus for measuring the shearing force and horizontal force ${ }^{(10)}$. The punch and die are made of hardened high chromium alloy tool steel and are carefully ground. The experimental apparatus has a vertical load cell and a horizontal load cell to measure the shearing force and horizontal force respectively. These load cells are attached to the experimental apparatus via linear guides. Figure 5 shows the calibration diagrams of the load cell. There is little interference between the two cells.
Table 1 Experimental conditions (flank surface)

\begin{tabular}{|l|c|}
\hline Clearance $\quad(\%)$ & $2,8,15$ \\
\hline Punch speed $\quad(\mathrm{mm} / \mathrm{s})$ & $0.01,0.05,0.21$ \\
\hline Kinematic viscosity $\left(\times 10^{-6} \mathrm{~m}^{2} / \mathrm{s}\right)$ & $5,60,420,2800,8300$ \\
\hline
\end{tabular}

Table 2 Experimental conditions (top surface)

\begin{tabular}{|l|c|}
\hline Clearance $\quad(\%)$ & 15 \\
\hline Punch speed $\quad(\mathrm{mm} / \mathrm{s})$ & $0.004,0.008,0.021$ \\
\hline Kinematic viscosity $\quad\left(\times 10^{-6} \mathrm{~m}^{2} / \mathrm{s}\right)$ & $5,60,420,2800,8300$ \\
\hline Compressive force $\quad(\mathrm{N})$ & $58,105,158$ \\
\hline
\end{tabular}

The punch displacements were measured using a linear resistance potentiometer mounted on the dieset. The metal sheet was pressed onto a die by using a blankholder with bolts, thus realizing the conditions shown in Figs. 2 and 3 .

(1) Coefficient of friction at punch flank $\left(\mu_{v}\right)$

The shearing force and horizontal force after separation were measured experimentally. Then, the coefficient of friction at the punch flank was calculated using Eq. (5).

(2) Coefficient of friction at punch face $\left(\mu_{n}\right)$

The coefficient of friction between the tool face and the material surface was also determined from sliding friction tests. Because the friction at the punch face is similar to the sliding friction, the coefficient of friction was determined by the following method. The material on the die was pressed to the surface of the punch by a compressive force. Then, the shearing force and horizontal force were measured while the punch moved up and down. Then, the coefficient of friction was calculated using Eq. (5).

\subsection{Experimental conditions}

The material of the specimens was a semihard aluminum plate (JIS:A1050BEH112). The specimens were rectangular, measuring $20 \mathrm{~mm}$ long and $15 \mathrm{~mm}$ wide with a thickness of $2 \mathrm{~mm}$. Experiments were carried out to confirm the influences of punch speed and lubricating oil on the coefficient of friction. The experimental conditions used to determine the coefficient of friction at the punch flank are shown in Table 1. Lubricant oil was applied to the surface of the specimen before shearing test. The experimental conditions for measuring the coefficient of friction at the punch face are shown in Table 2. It is thought that the speed of the material contacting the punch face is lower than that of the material contacting the punch flank. The coefficient of friction at the punch face was therefore determined by experiments with varying speeds for the punch flank. The influence of the compressive force on the coefficient of friction was also confirmed.

\section{Experimental Results}

\subsection{Experimental stability}

Experimental stability was confirmed using shearing 


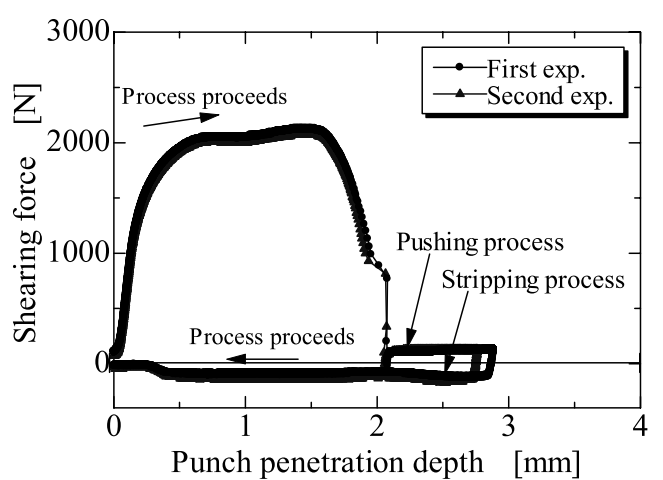

(a) Shearing force

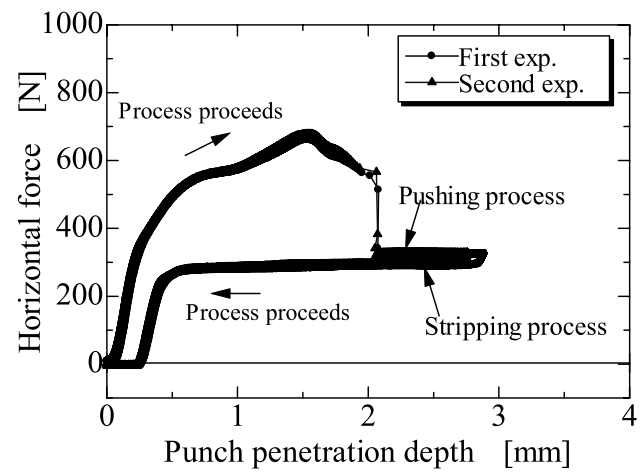

(b) Horizontal force

Fig. 6 Confirmation of experimental stability observed in shearing diagrams $(\mathrm{Cl}: 15 \%$, punch speed: $0.05 \mathrm{~mm} / \mathrm{s}$, kinematic viscosity: $60 \times 10^{-6} \mathrm{~m}^{2} / \mathrm{s}$ )

diagrams. Figure 6 shows the experimental results. The experimental results did not differ under the same experimental conditions. In the case of the experimental results with clearances of 2 and $8 \%$, experimental stability was also confirmed.

\subsection{Coefficient of friction between punch flank and virgin surface of specimen}

\subsubsection{Influence of clearance on coefficient of fric-}

tion Figure 7 shows a comparison of coefficients of friction obtained from the pushing and stripping processes. The coefficients of friction differ from each other, and that obtained from the pushing process is about 0.35 . Furthermore, clearance has little influence on the coefficients of friction obtained from the pushing process. On the other hand, the coefficient of friction obtained from the stripping process is about 0.28 . These results may be explained by the following two reasons. The first reason is that the linear guide has a high stiffness during compression and a low stiffness during tensile load application. The second reason may be the application of lubricant oil to the sheared surface, because the friction during the stripping process was the second friction occurring on the sheared surface.

From the above results, it is thought that the coefficient of friction at the punch flank is about 0.35 . The coefficient of friction obtained from the pushing process was

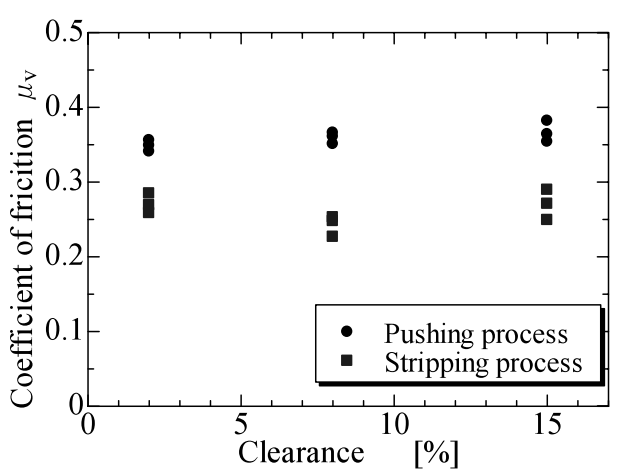

Fig. 7 Comparison of coefficients of friction obtained from pushing process and stripping process (punch speed: $0.05 \mathrm{~mm} / \mathrm{s}$, kinematic viscosity: $60 \times 10^{-6} \mathrm{~m}^{2} / \mathrm{s}$ )

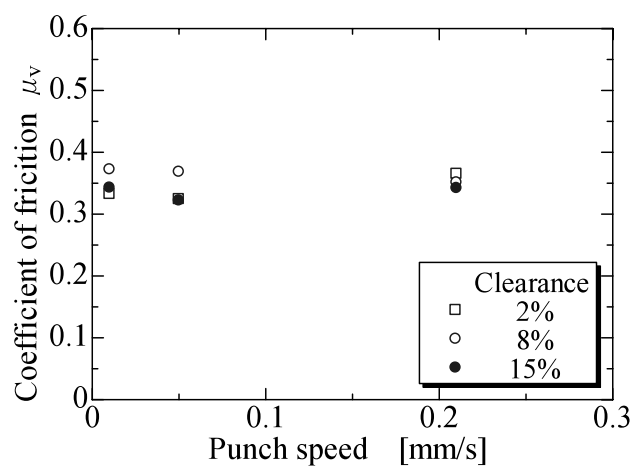

Fig. 8 Influence of punch speed on coefficient of friction (kinematic viscosity: $60 \times 10^{-6} \mathrm{~m}^{2} / \mathrm{s}$ )

used in subsequent investigations. The frictional stress with the coefficient of friction of 0.35 was about $35 \%$ of the shear yield stress when the material did not harden. Although further detailed examination is necessary, the coefficient of friction is thought to be constant because clearance has little influence on the coefficient of friction.

4.2.2 Influence of punch speed The effects of punch speed within the limits of $0.01-0.21 \mathrm{~m} / \mathrm{s}$ on the coefficient of friction were investigated. Figure 8 shows the effects of punch speed on the coefficient of friction. Punch speed has little influence on the coefficient of friction. The punch speed in this study differs from punch speeds at plants, which are between 0.1 and $0.5 \mathrm{~m} / \mathrm{s}$. However, it is already known that the punch speed has little influence on shearing characteristics in this range of speeds ${ }^{(11)}$. Therefore, the coefficients of friction obtained by this method are thought to be significant in practical use.

4.2.3 Influences of kinematic viscosity of lubricating oil and number of friction cycles on coefficient of friction The influence of the kinematic viscosity of lubricating oil on the coefficient of friction was investigated. Then, the influence of the number of friction cycles on the coefficient of friction was investigated by repeatedly moving the punch up and down. Figure 9 shows the influence of kinematic viscosity on the coefficient of 


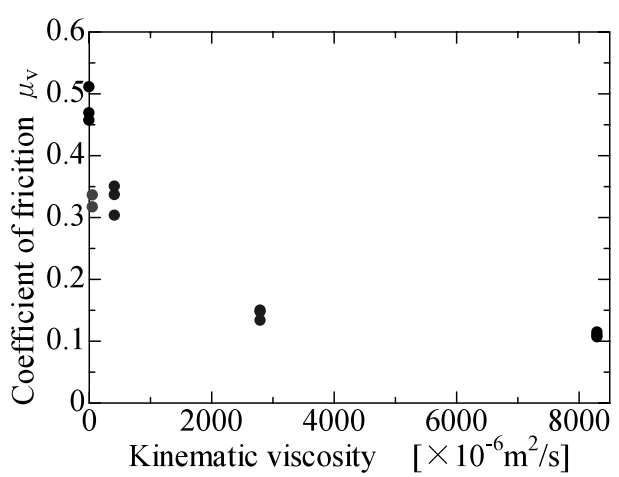

Fig. 9 Influence of kinematic viscosity on coefficient of friction (clearance: $15 \%$, punch speed: $0.05 \mathrm{~mm} / \mathrm{s}$ )

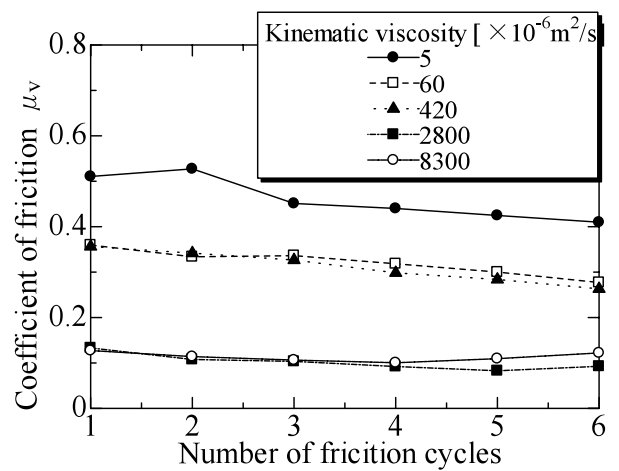

Fig. 10 Influence of number of friction cycles on coefficient of friction (clearance: $15 \%$, punch speed: $0.05 \mathrm{~mm} / \mathrm{s}$ )

friction obtained from the first pushing process. It is confirmed that the coefficient of friction decreases with increasing kinematic viscosity. Figure 10 shows the influence of the number of friction cycles on the coefficient of friction. It is confirmed that the coefficient of friction decreases with increasing number of friction cycles. This tendency was found to increase with decreasing kinematic viscosity. The reason for these results may be due to the reduction in friction force by the application of the lubricant oil to the interface.

Figure 11 shows a comparison of the sheared surfaces. There are traces of the punch tip when the kinematic viscosity is low, but there are thin wrinkles when the kinematic viscosity is high. This is due to shearing being carried out via the lubricant oil when the kinematic viscosity of lubricant oil is high, confirming that the coefficient of friction at the punch flank is changed by the type of lubricant oil.

\subsection{Coefficient of friction at punch face}

Figure 12 shows the friction force between the punch face and the surface of the specimen. Because the direction of the friction force is changed by changing the direction of the punch motion, the friction force changes to a negative value from a positive value. Observation of the material surfaces confirmed that there was no damage on the material surface, nor adhesion and seizing.

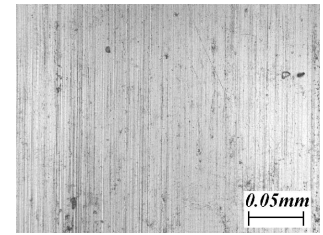

(a) $5 \times 10^{-6} \mathrm{~m}^{2} / \mathrm{s}$

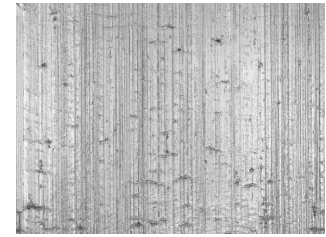

(c) $2800 \times 10^{-6} \mathrm{~m}^{2} / \mathrm{s}$

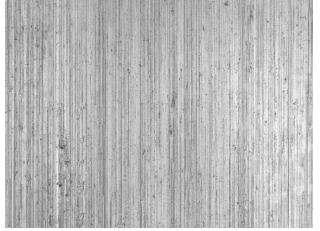

(b) $60 \times 10^{-6} \mathrm{~m}^{2} / \mathrm{s}$

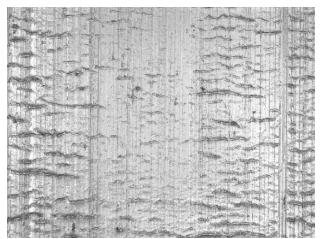

(d) $8300 \times 10^{-6} \mathrm{~m}^{2} / \mathrm{s}$
Fig. 11 Comparison of sheared surfaces (clearance: 15\%, punch speed: $0.05 \mathrm{~mm} / \mathrm{s}$ )

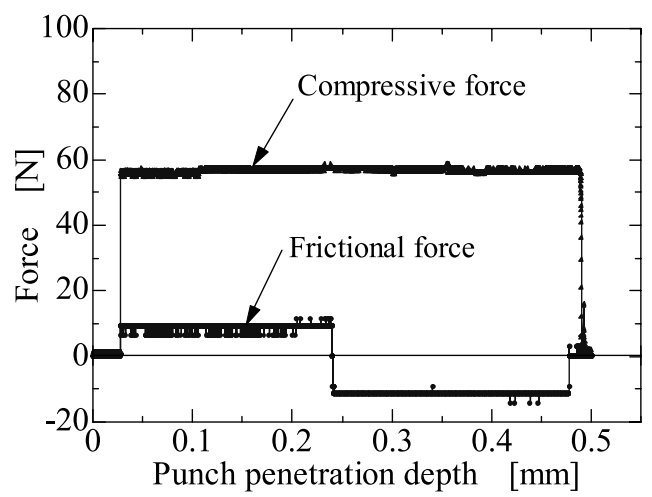

Fig. 12 Friction force diagrams (kinematic viscosity: $5 \times$ $10^{-6} \mathrm{~m}^{2} / \mathrm{s}$, punch speed: $4 \mu \mathrm{m} / \mathrm{s}$ )

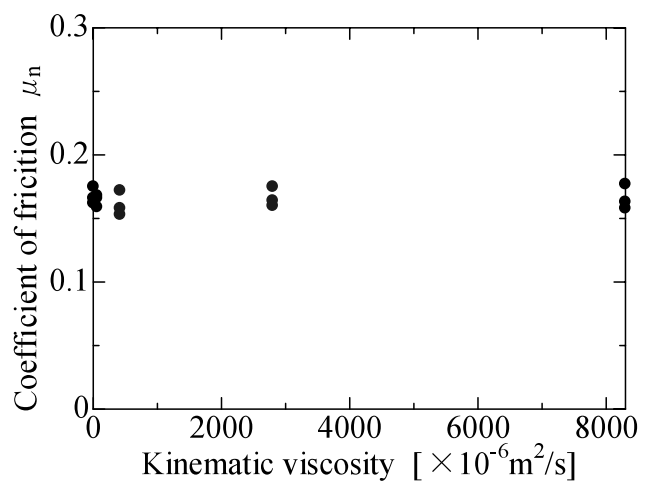

Fig. 13 Influence of kinematic viscosity on coefficient of friction (punch speed: $8 \mu \mathrm{m} / \mathrm{s}$, compressive force: $58 \mathrm{~N})$

Figures 13-15 show the coefficient of friction at the punch face. There is little influence of kinematic viscosity, pressure or punch speed on the coefficient of friction. The coefficient of friction ranges from 0.15 to 0.17 .

\section{Experiment and FEM Analysis to Confirm Rele- vance of Coefficient of Friction}

It is already known that the coefficient of friction at 


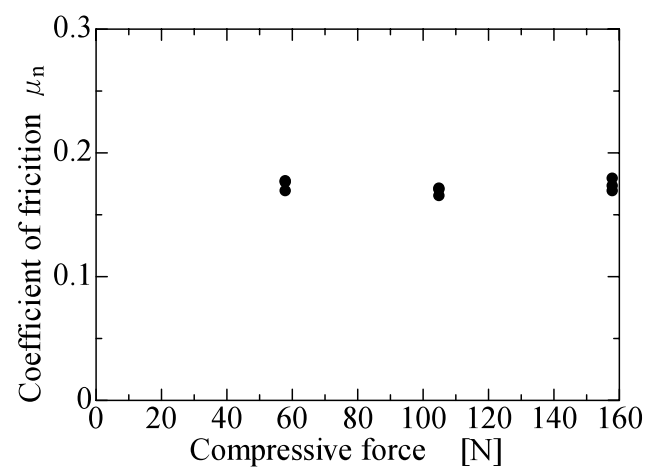

Fig. 14 Influence of pressure on coefficient of friction (kinematic viscosity: $60 \times 10^{-6} \mathrm{~m}^{2} / \mathrm{s}$, punch speed: $8 \mu \mathrm{m} / \mathrm{s})$

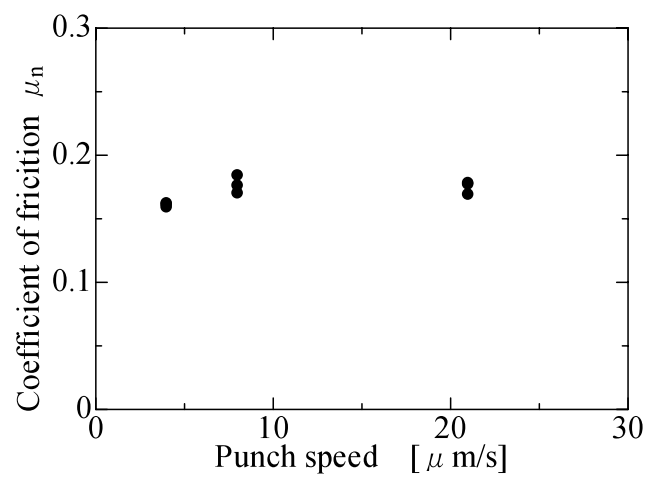

Fig. 15 Influence of punch speed on coefficient of friction (kinematic viscosity: $60 \times 10^{-6} \mathrm{~m}^{2} / \mathrm{s}$, compressive force: $58 \mathrm{~N}$ )

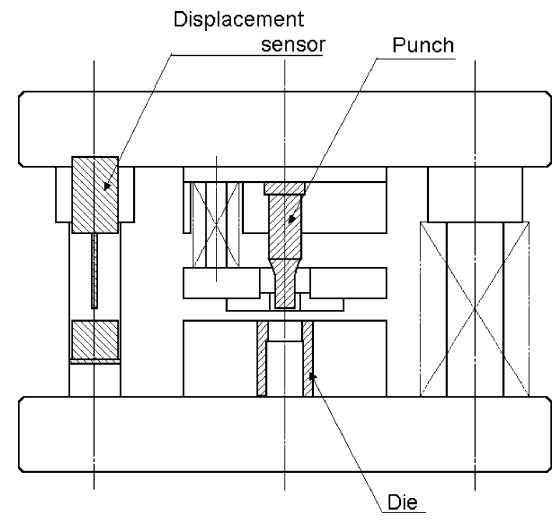

Fig. 16 Main part of shearing tool

the punch flank influences the shearing force of small-hole piercing ${ }^{(7),(8)}$. FEM analysis and experiments were therefore carried out on small-hole piercing to confirm the relevance of the coefficients of friction at the punch flank and face obtained by the proposed method.

\subsection{Experiment}

Figure 16 shows the main part of the shearing tool with punches of $2.0 \mathrm{~mm}$ diameter. The specimens were circular aluminum disks (JIS:A1050BEH112) of $35 \mathrm{~mm}$ diameter with a thickness of $4 \mathrm{~mm}$. Two clearances, $2 \%$ and $15 \%$ of the specimen thickness, were set by vary-

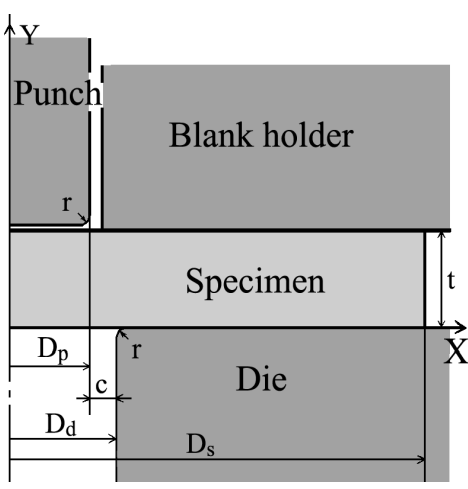

Fig. 17 Analyzed condition

ing the inside diameter of the die hole. The specimen was pressed onto the die by the blank holder. The force of the blank holder was $2243 \mathrm{~N}$. Paraffin lubricating oil (kinematic viscosity $90 \times 10^{-6} \mathrm{~m}^{2} / \mathrm{s}$ ) was applied to both surfaces of the specimen before piercing. Load was applied using a servomotor at a constant speed of $0.2 \mathrm{~mm} / \mathrm{s}$. Shearing forces were measured using strain gauges adhered to the punch flank, and punch displacements were measured using linear-resistance potentiometer sensors mounted onto the die set.

\subsection{FEM analysis}

Elastic-plastic FEM analysis was carried out using the FEM package DEFORM 2D. Although shearing is associated with the generation and propagation of fracture, the influence of the coefficient of friction on shearing force can most of the time be confirmed by analysis before fracturing occurs. For this reason, analysis is restricted to the period before fracturing occurs. The punch penetration depth analyzed was $4.0 \mathrm{~mm}$.

Figure 17 shows an axisymmetrical model for FEM analysis. The specimen was assumed to be an elastic plastic body and the tools assumed to be rigid bodies. The models of the punch and die had a small radius $r$ (Fig. 17) of $5 \mu \mathrm{m}$ on their cutting edge. The force of the blankholder was $2243 \mathrm{~N}$. The Coulomb friction rule was applied to the interfacial contact between the tool and the material. The coefficient of friction $\mu$ at the punch flank and die flank was assumed to be 0.35 . A coefficient of friction of 0.16 was assumed for other interfaces. Analysis assuming the coefficient of friction to be 0.1 at all interfaces was also carried out. To avoid reduced accuracy in large plastic deformation analysis, a remeshing scheme was included at points (a) or (b): (a) the increment of the punch penetration was found to reach $0.02 \mathrm{~mm}$, (b) the overlap between the elements and the tip of the punch and die reached $0.01 \mathrm{~mm}$.

The mechanical properties of the specimens were obtained by tensile tests using the same material as the piercing specimen. The results of the tensile tests indicated work-hardening characteristics for the plastic region as 


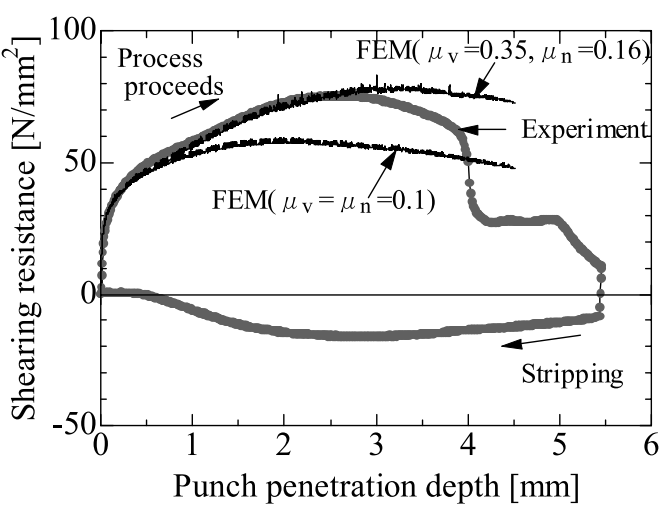

(a) Clearance $15 \%$

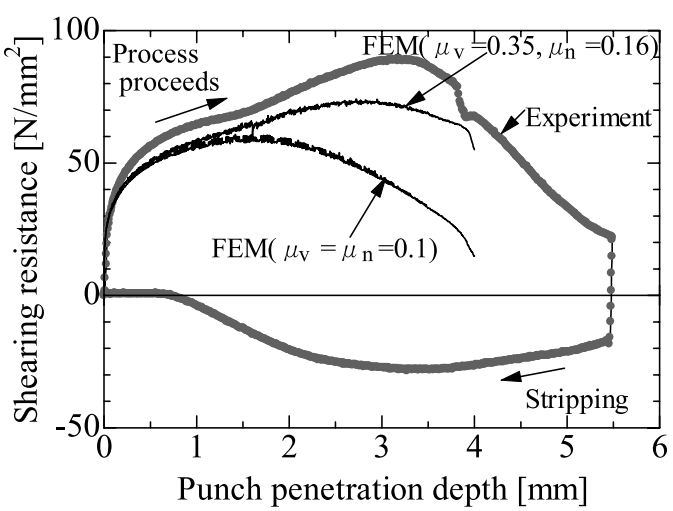

(b) Clearance $2 \%$

Fig. 18 Comparison of shearing diagrams between analytically and experimentally obtained results

shown by Eq. (6). A Young's modulus of $69 \mathrm{GPa}$ and a Poisson's ratio of 0.33 were used for the elastic region.

$$
\bar{\sigma}=43.1+119 \bar{\varepsilon}_{p}^{0.46}
$$

\subsection{Experimental and FEM results}

Figure 18 shows the results obtained by experiments and FEM analysis. When the clearance was 15\%, FEM results with the coefficient of friction of 0.1 differed from experimental results after a punch stroke of $1.0 \mathrm{~mm}$. On the other hand, the piercing curve obtained by FEM analysis with the coefficients of friction of 0.35 and 0.16 was in good agreement with the piercing curve obtained by experiments.

When the clearance was $2 \%$, FEM results with the coefficient of friction of 0.1 again differed from experimental results. The shearing resistance obtained by FEM decreased after a punch stoke of $1.5 \mathrm{~mm}$, although the shearing resistance obtained by experiments increased. On the other hand, the piercing curve obtained by FEM with the coefficients of friction of 0.35 and 0.16 was in good agreement with the piercing curve obtained by experiments. The shearing resistance obtained by FEM increased after the punch stroke of $1.5 \mathrm{~mm}$.

These results confirm the relevance of the coefficients of friction at the punch flank and face, although further detailed examination is still necessary.

\section{Conclusion}

The coefficient of friction between the tool and the material in shearing was investigated by experiments and FEM analysis. The following results were obtained.

1. A method for determining the coefficient of friction between the tool flank and the sheared surface in shearing was proposed. In this method, the vertical force and horizontal force need to be measured after the completion of the separation process, after which the coefficient of friction is defined as the ratio of vertical force to horizontal force. It was confirmed that the coefficient of friction can be obtained using this method.

2. It was also experimentally confirmed that the coefficient of friction at the punch flank differs from the coefficient of friction at the punch face. It was also confirmed that the kinematic viscosity of the lubricating oil influences the coefficient of friction. Using the proposed method, a coefficient of friction at the punch flank of about 0.35 was obtained using ordinary lubricating oil $\left(60,420 \times 10^{-6} \mathrm{~m}^{2} / \mathrm{s}\right)$. The coefficient of friction between the tool face and the material surface was also determined from a sliding friction test. The coefficient of friction at the punch face was about 0.16 .

3. The punch speed and clearance were found to have little influence on the coefficient of friction.

4. The results of FEM analysis, taking into consideration the coefficient of friction obtained by the proposed method, showed good agreement with the experimental results of the piercing of small holes.

\section{Acknowledgements}

This research was partly funded by Grant-In-Aid for Scientific Research (C) (No.16560101) from JSPS.

\section{References}

(1) Maeda, T., Theory of the Shearing Mechanism for Sheet-Metals with Punch and Die, J. Soc. Prec. Mech. of Jpn., (in Japanese), Vol.25, No.6 (1959), pp.248263.

( 2 ) Komori, K., Simulation of Shearing, J. JSTP, (in Japanese), Vol.38, No.433 (1997), pp.129-134.

( 3 ) Yukawa, N., Inukai, Y., Yoshida, Y., Ishikawa, T. and Jimma, T., Finite-Element Analysis of Blanking Process, J. JSTP, (in Japanese), Vol.39, No.454 (1998), pp.1129-1133.

(4) Hatanaka, N., Sekine, F. and Yamaguchi, K., Simulation of Crack Initiation and Propagation in Blanking of Sheet Metal, Trans. Jpn. Soc. Mech. Eng., (in Japanese), Vol.67, No.659, C(2001), pp.2352-2359.

( 5 ) Goijaerts, A.M., Govaert, L.E. and Baaijens, F.P.T., Evaluation of Ductile Fracture Models for Different Metals in Blanking, J. Mater. Process. Technol., Vol.110 (2001), pp.312-323.

( 6 ) Thipprakmas, S., Jin, M. and Murakawa, M., Investigation of Relationship between Blanking Conditions and 
Characteristics of Edge of Products Blanked by TwoStep Counter Blanking Processes-Study on Burr-Free Blanking I-, J. JSTP, (in Japanese), Vol.43, No.494 (2002), pp.209-213.

( 7 ) Sasada, M. and Aoki, I., Elastic-Plastic FEM Analysis for Piercing of Small Holes, Trans. Jpn. Soc. Mech. Eng., (in Japanese), Vol.69, No.678, C(2003), pp.496501.

( 8 ) Sasada, M., Kobayashi, H. and Aoki, I., Influence of Punch Geometry on Small Hole Piercing Characteristics, Trans. Jpn. Soc. Mech. Eng., (in Japanese), Vol.70, No.691, C(2004), pp.867-872.
(9) Osakada, K. and Murakami, F., A Method for Evaluating Tool Materials Against Seizure in Metal Forming, J. JSTP, (in Japanese), Vol.24, No.265 (1983), pp.195200.

(10) Aoki, I., Takahashi, T., Saitou, H., Gotoh, A. and Sakamoto, K., Fundamental Study on Clearance Compensation Effect and Side Force in Shearing, J. JSTP, (in Japanese), Vol.37, No.431 (1996), pp.1316-1321.

(11) Maeda, T., Velocity Effect on Shearing of Sheet Metal, J. Soc. Prec. Mech. of Jpn., (in Japanese), Vol.25, No.9 (1959), pp.439-451. 